\title{
The effect of dyspnea on recognition memory
}

2

3 Josef Sucec*, PhD; Michaela Herzog*, PhD; Omer Van den Bergh, PhD; Ilse Van Diest, PhD;

10 Running title: Dyspnea and recognition memory

12 Correspondence to: Josef Sucec, Mag. rer. nat.

13 Health Psychology

14 University of Leuven

15 Tiensestraat 102, box 3726

16 B-3000 Leuven (Belgium)

17 Telephone: $+32(0) 16330547$

18 Email: josef.sucec@kuleuven.be 


\begin{abstract}
1 Abstract
2 Dyspnea is a debilitating symptom in various prevalent diseases. Previous research demonstrated 3 several cognitive impairments in dyspneic patients including an impairment in recognition 4 memory. Even though some factors contributing to these impairments have already been identified 5 (e.g., smoking, medication), the relevance of dyspnea as one of those contributing factors is still 6 unclear. Thus, the goal of the current study was to investigate whether acute dyspnea impairs 7 recognition memory in a picture recognition task as indexed by reduced accuracy and a reduced 8 old-new effect in event-related potentials (ERPs) in the electroencephalogram (EEG). Fifty healthy 9 participants underwent a passive encoding phase without dyspnea induction, followed by the 10 picture recognition task performed during an unloaded baseline and a resistive load induced 11 dyspnea condition while EEG was continuously measured. Results indicated comparable accuracy 12 during the baseline and dyspnea condition. A reduced fronto-central old-new effect during dyspnea 13 compared to baseline was found for ERPs in the latency ranges 350-500, 500-800, 800-1100, and 14 1110-1400 ms. These findings suggest that dyspnea influences the process of familiarity (350-500 $15 \mathrm{~ms})$ and recollection (500-800 ms) as well as post-retrieval processes (800-1100 and 1100-1400 $16 \mathrm{~ms}$ ), highlighting a potential impairing effect of acute dyspnea on recognition memory. 17
\end{abstract}

18 Keywords: Recognition memory, Dyspnea, Breathlessness, EEG 


\section{Introduction}

2 Dyspnea (= breathlessness) is a common and aversive bodily sensation in various 3 cardiopulmonary, neuromuscular, and other diseases and has widespread impairing effects on

4 functioning in daily life (American Thoracic Society, 1999; Kessler et al., 2011; Parshall et al.,

5 2012). Research demonstrated impairments for a wide range of cognitive functions in diseases

6 where dyspnea is highly prevalent such as in chronic obstructive pulmonary disease (COPD)

7 (Cleutjens, Janssen, Ponds, Dijkstra, \& Wouters, 2014; Cleutjens et al., 2016; Dodd, Getov, \&

8 Jones, 2010; van Beers, Janssen, Gosker, \& Schols, 2018) or asthma (Irani, Barbone, Beausoleil,

$9 \&$ Gerald, 2017). Several factors contributing to cognitive impairments in these patients such as

10 age, education level, medication, comorbidities, or hypoxia (= deprived oxygen supply in tissue)

11 have been already identified (Celsis, 2000; Dodd et al., 2010; McIntyre et al., 2013). For example,

12 COPD patients might show cognitive impairments due to their typically older age (Celsis, 2000),

13 comorbid depression (McIntyre et al., 2013), medication usage such as opiates (Raghavan, Webb,

14 Amornputtisathaporn, \& O'Donnell, 2011), or hypoxia (Huppert, 1982; Moss, Franks, Briggs,

15 Kennedy, \& Scholey, 2005), with the latter leading to cognitive impairment in 77 percent of COPD

16 patients (Grant, Heaton, McSweeny, Adams, \& Timms, 1982 as cited in Dodd et al., 2010).

17 However, the effect of acute dyspnea itself on cognitive functioning is less well explored. So far,

18 a first set of studies demonstrated that dyspnea has an impairing effect on cognitive functioning in

19 healthy subjects including picture processing (Juravle, Reicherts, Riechmann-Weinstein, Wieser,

20 \& von Leupoldt, 2017; Juravle et al., 2014), inhibition (Sucec, Herzog, Van Diest, Van den Bergh,

21 \& von Leupoldt, 2018b), face recognition (Vinckier, Morélot-Panzini, \& Similowski, 2018), and

22 locomotor performance (Nierat et al., 2016). Furthermore, already the fearful anticipation of

23 dyspnea can lead to impairments in error-processing (Sucec, Herzog, Van Diest, Van den Bergh,

$24 \&$ von Leupoldt, 2018a). Since these studies reflect only a small fraction of cognitive functions

25 (Eysenck \& Keane, 2000), future studies exploring other cognitive domains are warranted.

27 Overall, cognitive impairment in dyspneic patients is paralleled by a decline in active recall and 28 passive recognition memory (Incalzi et al., 1997). Recognition memory is essential for the ability

29 to assess whether an item is new or has been encountered before (Clark, 2013), which might be

30 important in disease management. For example, patients usually receive detailed information from

31 medical staff about their illness and the subsequently required treatment procedures such as 
medication usage, which are essential to be accurately remembered in daily life for treatment

2 success (Kessels, 2003). Patients suffering from COPD show worse task performance in 3 recognition memory compared to healthy controls (Incalzi et al., 1997). This is problematic

4 because the amount of immediately forgotten medical information can already be higher than 40

5 percent in non-dyspneic patients (Kessels, 2003; Mcguire, 1996) and it might be assumed that

6 dyspnea leads to a further worsening of this percentage due to a dyspnea-cognition interference

7 (Nierat et al., 2016; Sucec et al., 2018b). However, the direct effect of acute dyspnea on recognition

8 memory has never been explored.

10 Recognition memory is commonly subdivided into the slower process of recollection, where 11 detailed recall of previously studied information is absolutely essential, and the faster process of 12 familiarity, which varies according to the closeness between presented cues and previously studied 13 information (Rugg \& Curran, 2007; Shiffrin \& Steyvers, 1997). Many researchers consider these 14 two processes as independent from each other during retrieval and only minimally overlapping 15 during the encoding phase (Yonelinas, 2002). The advances in cognitive neuroscience and the 16 usage of the event-related potential (ERP) technique in the electroencephalogram (EEG) allow 17 distinguishing between these two processes (Rugg \& Curran, 2007). So far, the effects of dyspnea 18 on the ERPs related to recognition memory and its two underlying processes, familiarity, and 19 recollection, have not yet been examined.

21 Recognition memory is typically investigated by old-new paradigms, where participants have to 22 indicate whether they have encountered a presented item (e.g., words, pictures) before (= old) or 23 not (= new) (Curran, 1999; Finnigan, 2002; Friedman \& Johnson, 2000; Johansson, Mecklinger, 24 \& Treese, 2004; Maratos, Allan, \& Rugg, 2000; Rugg \& Curran, 2007; Van Strien, Langeslag, 25 Strekalova, Gootjes, \& Franken, 2009; Weymar, Löw, \& Hamm, 2011; Xu, Zhang, Li, \& Guo, 26 2015). Recognition memory is typically operationalized as behavioral performance indexed as 27 accuracy according to signal-detection theory (Abdi, 2007; Malmberg, 2008), and as an old-new 28 effect in the EEG that can be expressed as an old-new difference score of ERPs elicited by these 29 items (e.g., Weymar, Bradley, Hamm, \& Lang, 2013). Importantly, overall accuracy is reduced 30 when an aversive bodily symptom such as acute pain is introduced. Specifically, more false alarms 31 during acute pain compared to a baseline condition have been demonstrated (Kuhajda, Thorn, 
1 Klinger, \& Rubin, 2002). Since pain shares many characteristics with dyspnea including the

2 threatening and aversive nature, as well as similar underlying emotion-related brain networks

3 (Banzett \& Moosavi, 2001; Gracely, Undem, \& Banzett, 2007; von Leupoldt \& Dahme, 2007; von

4 Leupoldt et al., 2009) similar effects of dyspnea on recognition memory performance might be

5 expected. In the EEG, participants typically show an old-new effect during the recognition memory

6 task such that correctly identified old items elicit a more positive going ERP deflection compared

7 to correctly identified new items (e.g., Curran, 1999; Rugg \& Curran, 2007; Xu et al., 2015). The

8 latency window for this effect varies widely across studies with a typical latency range between

9 300-1400ms (Maratos et al., 2000; Schloerscheidt \& Rugg, 1997; Xu et al., 2015). It is assumed

10 that the old-new effect relates to the correct recognition of the presented items with early latency

11 windows $(\approx 300-500 \mathrm{~ms})$ reflecting familiarity and later latency windows $(\approx 500-800 \mathrm{~ms})$

12 reflecting subsequent recollection followed by post-retrieval processes (Johansson et al., 2004;

13 Maratos et al., 2000; Mecklinger, 2000; Rugg \& Curran, 2007).

15 The present study investigated whether experimentally induced dyspnea would impair recognition

16 memory in healthy participants. Dyspnea was induced by inspiratory resistive loaded breathing

17 and compared to an unloaded baseline condition while participants were performing a picture

18 recognition task. Based on the findings from pain research (Kuhajda et al., 2002) and a potential

19 dyspnea-cognition interference (Nierat et al., 2016; Sucec et al., 2018b; Sucec, Herzog, Van den

20 Bergh, Van Diest, \& von Leupoldt, 2019) we expected reduced accuracy during dyspnea, which

21 would be paralleled by a reduced old-new effect in the ERPs. In an additional exploratory analysis

22 reaction times were investigated.

24 Methods

\section{Participants}

2750 healthy participants (41 females) with normal or corrected to normal vision took part in the 28 current study in return for either course credits or $16 €$ as compensation. Exclusion criteria included 29 a history of self-reported acute or chronic disorders. Additional exclusion criteria were nicotine 30 consumption, medication usage, pregnancy, and alcohol consumption 24 hours prior to testing. 31 Normal lung function was confirmed prior to testing via standard spirometry (Miller et al., 2005). 
1 Ethical approval for this study was obtained from the Social and Societal Ethics Committee of the

2 University of Leuven (G-2016-02-484).

4 Passive encoding phase

5 During the passive encoding phase, 160 color pictures of humans originating from the International Affective Picture System (IAPS, Lang, Bradley, \& Cuthbert, 2008) and a recently developed visual stimuli database $^{1}$ (Herzog, Sucec, Van Diest, Van den Bergh, Chenivesse, et al., 2018) were

8 presented in four blocks of 40 pictures each in a resolution of $2560 \times 1440$ pixels. The picture order was semi-randomized within each block. Pictures were presented for $4000 \mathrm{~ms}$ and followed by a

10 fixation cross with jittered presentation time (mean: $2000 \mathrm{~ms}$; range: 1800-2200 ms). The total

11 duration of each block was $4 \mathrm{~min}$. While passively viewing the pictures, participants were unaware

12 of the subsequent picture recognition task.

\section{Picture recognition phase}

15 During the picture recognition phase, 160 pictures from the passive encoding phase (= "old") and

16160 matched new pictures (= "new") were presented. The "new" pictures were matched to the

17 "old" pictures based on affective valence, arousal, picture content, and picture composition. The

18 total of 320 pictures was divided into four blocks each containing 80 pictures. The pictures in each

19 block were presented in semi-random order consisting of 40 "old" and 40 "new" pictures. Two of

20 the blocks of the picture recognition task were performed during an unloaded baseline condition

21 and two during a dyspnea condition. In all four blocks, participants were breathing through a

22 breathing circuit. Baseline and dyspnea blocks were alternated (either "A-B-A-B" or "B-A-B-A")

23 to reduce respiratory muscle fatigue with a counterbalanced order across participants. Similar to

24 previous research (Alexander-Miller \& Davenport, 2010; Brack, Jubran, \& Tobin, 1998; Herzog,

25 Sucec, Van Diest, Van den Bergh, Chan, et al., 2018) dyspnea was induced during the dyspnea

26 condition via breathing through an inspiratory resistive load (Hans Rudolph, Inc., Shawnee, USA)

27 of $20 \mathrm{cmH}_{2} \mathrm{O} / 1 / \mathrm{s}$ that was applied to the breathing circuit. During each block, participants had to

28 indicate via button press on a response box whether pictures had already been presented (= "old")

29 or not (= "new") during the passive encoding phase. Again, each picture was presented in a

$302560 \times 1440$-pixel resolution until a response was given or for maximally $2000 \mathrm{~ms}$. Subsequently,

\footnotetext{
${ }^{1}$ The technical report for this database is currently in preparation.
} 
1 each block of the picture recognition task lasted maximally 2 min and $40 \mathrm{~s}$. Responses for each

2 picture were allowed from picture onset until $2000 \mathrm{~ms}$ after picture onset.

4 Ratings

5 Dyspnea was explained to participants as "difficult and uncomfortable breathing". Dyspnea was rated via a modified Borg scale (Borg, 1982) ranging from 0 (= "not noticeable") to 10 (= "unbearable (impossible to tolerate)". Additionally, participants rated their affective state by

8 indicating their affective valence ( 1 = "unpleasant" to 9 = "pleasant") and arousal ( 1 = "calm" to 99 = "aroused") via the 9-point Self-Assessment Manikin (Bradley \& Lang, 1994). Furthermore, 10 participants rated the difficulty of the recognition memory task ( $1=$ "not difficult at all" to $7=$ 11 "extremely difficult") and how motivated they were to perform the task on a 7-point Likert scale $12 \quad(1=$ "not motivated at all" to $7=$ "extremely motivated"). All ratings referred to the preceding 13 block.

\section{Breathing circuit}

16 During the picture recognition phase, participants were breathing via a mouthpiece through the 17 breathing circuit with a nose clip preventing nasal respiration. The breathing circuit consisted of a 18 two-way T-shaped non-rebreathing valve (Hans Rudolph Inc., Shawnee, USA). The expiratory 19 port of the non-rebreathing valve was connected via a sampling line to a capnograph (VacuMed, $20 \mathrm{CO} 2$ Analyzer, Gold Edition, Ventura, USA) measuring end-tidal $\mathrm{CO}_{2}\left(\mathrm{ETCO}_{2}\right)$. Furthermore, at 21 the center of the non-rebreathing valve, mouth pressure was measured. The inspiratory port of the 22 non-rebreathing valve was connected via tubing to a pneumotachograph (Hans Rudolph Inc., 23 Shawnee, USA) measuring airflow and subsequently to a loading manifold used to apply the 24 inspiratory resistive load (Hans Rudolph Inc., Shawnee, USA). During all blocks of the recognition 25 memory phase airflow, mouth pressure, and $\mathrm{ETCO}_{2}$ were measured continuously. To calculate the 26 respiratory variables including breathing frequency $(\mathrm{f})$, inspiratory time $\left(\mathrm{T}_{\mathrm{I}}\right)$, tidal volume $\left(\mathrm{V}_{\mathrm{T}}\right)$, 27 mean airflow ( $\left.\mathrm{V}^{\prime}\right)$, peak inspiratory mouth pressure ( $\left.\mathrm{P}_{\max }\right)$, and $\mathrm{ETCO}_{2}$, AcqKnowledge 4.2 28 (Biopac, Goleta, USA) was used.

\section{Psychophysiological recordings and data reduction}

31 During the picture recognition phase, the 129-channel EEG (Philips Electrical Geodesics Inc., 
1 Eugene, USA) was continuously recorded with a sampling rate set at $250 \mathrm{~Hz}$ and $\mathrm{Cz}$ as reference. 2 Impedance was kept below $50 \mathrm{k} \Omega$. Subsequently, Brain Electrical Source Analysis Research 6.0 3 (BESA GmbH, Gräfelfing, Germany) was used to process the EEG data offline. Raw data were 4 filtered using a half amplitude cut-off with a high-pass filter of $0.01 \mathrm{~Hz}$ (forward-phase 5 Butterworth filter, $6 \mathrm{~dB}$ /octave roll-off), a low-pass filter of $40 \mathrm{~Hz}$ (zero-phase Butterworth filter, $24 \mathrm{~dB} /$ octave roll-off), and an additional notch filter of $50 \mathrm{~Hz}$ ( $2 \mathrm{~Hz}$ width). Artifacts were corrected using spatial filters implemented in BESA designed to separate artifacts and brain 8 activity (Ille, Berg, \& Scherg, 2002). Brain activity was estimated by scanning the data in intervals of $16 \mathrm{~ms}$. Data were considered brain activity when the criteria of correlation (correlation between data and artifact $<.50)$ and amplitude $( \pm 100 \mu \mathrm{V})$ were fulfilled. Spatial topographies describing

11 the artifacts were manually selected. Next, an adaptive algorithm based on principal component analysis described in Ille, Berg, \& Scherg (2002) was applied. All principal component analyses

13 explaining more than $10 \%$ of the variance were retained. Then, the recorded EEG data was 14 deconstructed into topographies separating artifact and brain activity via a linear combination 15 resulting in the subtraction of artifact activity and subsequently artifact removal. A comparable 16 number of artifacts, specifically blink artifacts $(\mathrm{t}(38)=0.78, \mathrm{p}=.52, r=.13)$, was removed in the 17 baseline $(\mathrm{M}=65.18, \mathrm{SD}=48.66)$ and dyspnea condition $(\mathrm{M}=60.97, \mathrm{SD}=38.23)$. Based on 18 established recommendations for high-density EEG (Dien, 1998; Luck, 2014), data were rereferenced to the average reference. Stimulus-locked epochs ranging from -200 to $2000 \mathrm{~ms}$ were extracted and averaged for correctly categorized pictures. Epochs that did not fulfill the criteria for 21 amplitude $(<200 \mu \mathrm{V} / \mathrm{ms})$, gradient $(>75 \mu \mathrm{V} / \mathrm{ms})$, and low signal $(<0.01 \mu \mathrm{V} / \mathrm{ms})$ were automatically excluded from averaging. For the ERPs of the baseline condition on the average 24 trials (range: 11-44) were rejected for the hits and 15 trials (range: 6-35) for the correct rejection 24 while for the dyspnea condition 24 trials (range: 9-56) were rejected for the hits and 16 trials 25 (range: 3-41) for the correct rejection. The average number of trials of the ERPs was for the 26 baseline condition 56 trials (range: 36-69) for the hits and 65 trials (range: 45-74) for the correct 27 rejection and in the dyspnea condition 56 trials (range: 24-71) for the hits and 64 trials (range: 3928 77) for the correct rejection. The pre-stimulus interval ranging from -100 to $0 \mathrm{~ms}$ was used as 29 baseline. Similar to previous research (Rugg et al., 1998; Weymar et al., 2011) and visual 30 inspection of the signal, fronto-central electrodes (electrodes left hemisphere: 7, 13, 20, 28, 29, 30, 3135 ; electrodes right hemisphere: 105, 106, 110, 111, 112, 117, 118) and centro-parietal electrodes 
1 (electrodes left hemisphere: 31, 37, 42, 52, 53, 54, 60, 61, 67; electrodes right hemisphere: 77, 78, $279,80,85,86,87,92,93$ ) were selected for each hemisphere (Figure 1). The hemisphere was 3 considered based on previous literature which found hemispheric differences for recollection and 4 post-retrieval processes (Johansson et al., 2004; Maratos et al., 2000; Rugg \& Curran, 2007; 5 Schloerscheidt \& Rugg, 1997). The electrodes were then clustered for the latency windows 350-

\#\#\#Figure 1\#\#\#

\section{Procedure}

12 Before any data was collected, all participants signed the informed consent and exclusion criteria 13 form and normal pulmonary function was confirmed via standard spirometry. Then, the EEG net 14 was mounted, and participants were seated, with their upper body and feet being supported, approximately $148 \mathrm{~cm}$ in front of a 32-inch standard screen. Subsequently, participants underwent the four blocks of the passive encoding phase followed by a short break. Afterwards, detailed 17 instructions regarding the picture recognition phase followed and participants were familiarized 18 with the inspiratory resistive load. Then, the four blocks of the picture recognition phase followed.

19 Two of these blocks were performed during unloaded baseline breathing while two other blocks 20 were performed during dyspnea. Each block was followed by a short resting period during which 21 the ratings of dyspnea, affective state, task difficulty, and task motivation were obtained. Finally, 22 participants were thanked and debriefed.

\section{Statistical analysis}

25 Due to technical malfunction leading to failure to store sufficient data, ten participants had to be 26 excluded from data analysis. Moreover, one participant was excluded from data analysis due to a 27 procedural mistake committed by the experimenter. Thirty-nine participants (31 females) with a mean age of 23.51 years $(\mathrm{SD}=7.53$ ) were included in the final analysis which was performed using IBM SPSS Statistics 25. All ratings, respiratory variables as well as behavioral measures 30 and ERPs of the picture recognition phase were averaged across the two baseline and the two 31 dyspnea blocks, respectively. To confirm successful dyspnea induction, ratings of dyspnea, 
1 valence, and arousal, as well as respiratory variables, were compared between the baseline and 2 dyspnea condition using dependent t-tests. Additionally, the ratings of task difficulty and task 3 motivation were compared between conditions using dependent t-tests. In case not all assumptions

4 for dependent t-tests were met, non-parametric Wilcoxon signed-rank tests were applied. To 5 investigate recognition memory, accuracy and ERPs were explored. Accuracy rates were analyzed 6 based on signal detection theory (Abdi, 2007; Malmberg, 2008) including the indices hit rate (H), 7 false alarm rate $(\mathrm{FA})$, recognition accuracy $(\mathrm{Pr}=\mathrm{H}-\mathrm{FA})$, and response bias $(\mathrm{Br}=\mathrm{p}(\mathrm{FA}) / \mathrm{p}(1-\mathrm{Pr}))$.

8 To investigate a potential dyspnea effect on the accuracy indices, dependent t-tests were calculated.

9 For the ERPs, an old-new mean amplitude difference score (= old minus new) for correctly 10 categorized items was calculated. For each brain region (fronto-central, centro-parietal) and 11 latency range (350-500, 500-800, 800-1100, 1100-1400 ms) separate 2 × 2 repeated measures 12 ANOVAs were computed for the old-new difference scores with the within factors dyspnea 13 (baseline, dyspnea) and hemisphere (left, right). For the exploratory analysis of reaction times, a $142 \times 2$ repeated measures ANOVA with the within factors dyspnea (baseline, dyspnea) and 15 familiarity (old, new) was calculated. Only correctly categorized items were analyzed for the 16 reaction times. The effect size used for the ANOVAs and dependent t-tests/Wilcoxon signed-rank 17 tests were $\eta_{\mathrm{p}}^{2}$ and $\mathrm{r}$, respectively. The level of significance was set at $\alpha=.05$.

\section{Results}

\section{Ratings}

22 Higher dyspnea ratings were found for the dyspnea compared to the baseline condition $(z=-4.69$, $23 p<.001, r=.53)$. Moreover, lower valence ratings, indicating more unpleasantness, $(\mathrm{t}(38)=4.93$, $24 p<.001, r=.62)$ and higher arousal ratings $(\mathrm{t}(38)=-2.23, p=.032, r=.34)$ were found for the

25 dyspnea compared to the baseline condition. While for the dyspnea condition higher task difficulty 26 was reported $(\mathrm{t}(38)=-2.42, p=.021, r=.37)$, the motivation to perform the task was comparable 27 between both conditions ( $\mathrm{t}(38)=0.30, p=.77, r=.05$; Table 1$)$.

\section{Respiratory variables}


1 The analysis of the respiratory variables demonstrated lower $\mathrm{f}(\mathrm{z}=-4.49, p<.001, r=.50)$ and $\mathrm{V}$ '

$2(\mathrm{z}=-5.32, p<.001, r=.60)$ as well as higher $\mathrm{T}_{\mathrm{I}}(\mathrm{t}(38)=-6.40, p<.001, r=.72), \mathrm{P}_{\operatorname{Imax}}(\mathrm{z}=-5.44$,

$3 p<.001, r=.62)$, and $\mathrm{ETCO}_{2}(\mathrm{z}=-4.08, p<.001, r=.46)$ for the dyspnea compared to the baseline

4 condition. Values for $\mathrm{V}_{\mathrm{T}}$ were comparable between both conditions $(\mathrm{t}(38)=1.15, p=.26, r=.18$;

5 Table 2).

\#\#\#Table 2\#\#\#

9 Behavioral performance

10 The accuracy indices $\mathrm{H}(\mathrm{t}(38)=-1.11, p=.28, r=.18)$, FA (t(38) $=-0.18, p=.86, r=.03), \operatorname{Pr}$

$11(\mathrm{t}(38)=-0.86, p=.40, r=.14)$, and $\operatorname{Br}(\mathrm{t}(38)=-0.47, p=.64, r=.08)$ were comparable between

12 the baseline and dyspnea condition (Table 3). The exploratory analysis of the reaction times

13 showed a main effect for familiarity $\left(F(1,38)=24.54, p<.001, \eta^{2}{ }_{p}=.39\right)$ with faster reaction

14 times for old compared to new pictures (Table 4). No significant main effect for the factor dyspnea $15(\mathrm{p}=.39)$ or an interaction effect was observed $(\mathrm{p}=.92)$.

\#\#\#Table 3\#\#\#

\#\#\#Table 4\#\#\#

ERPs

22 Figure 2 illustrates ERPs for old and new pictures during both experimental conditions at fronto23 central and centro-parietal sites showing the typical enhanced positivity for old compared to new 24 pictures.

\#\#\#Figure 2\#\#\#

\section{Fronto-central}

29 A main effect of the factor dyspnea was found for the latency ranges $350-500 \mathrm{~ms}(F(1,38)=4.87$, $\left.30 p=.033, \eta_{\mathrm{p}}^{2}=.11\right), 500-800 \mathrm{~ms}\left(F(1,38)=6.89, p=.012, \eta_{\mathrm{p}}^{2}=.15\right), 800-1100 \mathrm{~ms}(F(1,38)=$ $\left.314.34, p=.044, \eta_{\mathrm{p}}^{2}=.10\right)$, and $1100-1400 \mathrm{~ms}\left(F(1,38)=6.55, p=.015, \eta_{\mathrm{p}}^{2}=.15\right.$; Figure 3,4$)$. 
1 Furthermore, for the latency ranges $500-800\left(F(1,38)=6.24, p=.017, \eta_{\mathrm{p}}^{2}=.14\right)$ and $1100-1400$

$2\left(F(1,38)=6.34, p=.016, \eta_{\mathrm{p}}^{2}=.14\right)$ a main effect for the factor hemisphere was found. For the

3 latency 500-800 ms larger old-new differences were observed for the left hemisphere while for

4 1100-1400 ms larger old-new differences were found for the right hemisphere (Table 5). No

5 significant interaction effects were observed $(\mathrm{p}>.05)$.

6

\section{Centro-parietal}

14 Neither a significant main effect nor a significant interaction effect was observed for any latency 15 range $(p>.05$; Table 6$)$.

\section{\#\#\#Figure 3\#\#\#}

\#\#\#Figure 4\#\#\#

\section{\#\#\#Table 5\#\#\#}


1 Diest, Van den Bergh, \& von Leupoldt, 2019). The successful dyspnea induction was further 2 supported by respiratory variables demonstrating lower $\mathrm{f}$ and $\mathrm{V}^{\prime}$ as well as higher $\mathrm{T}_{\mathrm{I}}$ and $\mathrm{P}_{\mathrm{Imax}}$ 3 during the dyspnea compared to the baseline condition. These respiratory related findings are in 4 line with previous research using similar dyspnea induction methods (Alexander-Miller \& 5 Davenport, 2010; Alius, Pané-Farré, Von Leupoldt, \& Hamm, 2013; Herzog, Sucec, Vukovic, et al., 2019; Peiffer, Costes, Hervé, \& Garcia-Larrea, 2008). A small, but statistically significant difference for $\mathrm{ETCO}_{2}$ was found, which was within the normal range and, thus, presumably had 8 no effect on the outcome measures (Bloch-Salisbury, Lansing, \& Shea, 2000)

Confirming our hypothesis, dyspnea affected the ERPs related to recognition memory. A reduced

11 old-new effect during dyspnea was found in fronto-central regions in all analyzed time windows

12 (350-500, 500-800, 800-1100, 1100-1400 ms), but not in centro-parietal regions. This is in line

13 with research showing more frontal activation for picture stimuli in old-new paradigms

14 (Schloerscheidt \& Rugg, 1997). Furthermore, this research (Schloerscheidt \& Rugg, 1997)

15 demonstrated stronger old-new differences left hemispheric in earlier latency windows and right

16 hemispheric in later latency windows. A similar pattern was also observed in the current study with

17 stronger old-new effects for the left hemisphere in the latency window 500-800 ms, which shifted

18 towards the right hemisphere where it became pronounced in the latency window 1100-1400 ms.

19 Overall, the occurring differences in all time windows between conditions suggest that dyspnea

20 influences the process of familiarity $(350-500 \mathrm{~ms})$ and recollection $(500-800 \mathrm{~ms})$ as well as post-

21 retrieval processes (800-1400 ms) (Johansson et al., 2004; Maratos et al., 2000; Mecklinger, 2000;

22 Rugg \& Curran, 2007), which is indicative of a potential impairing effect of acute dyspnea on 23 recognition memory.

25 The reduced old-new effect in the ERPs caused by dyspnea can be most likely attributed to a 26 dyspnea-cognition interference (Nierat et al., 2016; Sucec et al., 2018b). Based on the dyspnea27 cognition interference it is assumed that dyspnea draws attentional resources which then cannot be 28 allocated to a cognitive task performed in parallel. This attentional shift potentially causing 29 dyspnea-cognition interference is further supported by our observation of increased ratings of task 30 difficulty for the dyspnea compared to the baseline condition while the motivation to perform the 31 task remained comparable. Moreover, it seems unlikely that the current old-new effect was affected 
1 by emotions (McGaugh, 2004; Ochsner, 2000; Sterpenich et al., 2009) that were evoked by the 2 dyspnea induction. The reasons are twofold: Firstly, the ratings of negative valence and arousal 3 during the dyspnea condition are suggestive of a relatively mild negative emotional state. 4 Secondly, research usually shows a boosting effect of negative emotions on familiarity and 5 recollection (Ochsner, 2000), which is in contrast to the present finding that dyspnea reduces the old-new effect in the EEG. Since blink artifacts and overall rejected trials were comparable between the baseline and dyspnea condition, it seems highly unlikely that the current findings can

8 be attributed to differences in data quality between conditions.

Although we observed that dyspnea attenuates the old-new effect in the ERPs, we did not find the expected effect of dyspnea on accuracy (Kuhajda et al., 2002; Sucec et al., 2018b) nor any effect on reaction times. Interestingly, we found, even though not significant, slightly faster reaction

13 times during dyspnea together with higher arousal ratings which might point into the direction of 14 a facilitation effect of dyspnea. The non-significant behavioral findings are in contrast to previous pain research (Kuhajda et al., 2002) which showed that acute pain reduces the accuracy in a recognition memory task. More specifically, during the acute pain condition, the false-alarm rate

17 was increased compared to the baseline condition (Kuhajda et al., 2002). Furthermore, respiratory

18 research indicated behavioral impairments of dyspnea on other cognitive functions (e.g., Juravle et al., 2014; Nierat et al., 2016; Sucec et al., 2018b). For example, experimental dyspnea reduced the accuracy in a task measuring inhibition (Sucec et al., 2018b). The current contrasting findings might be due to the induced level of dyspnea in the present study, which was still in a moderate range during the dyspnea condition and might have been too low to result in any stronger behavioral effect in healthy young individuals. For example, in the study by Sucec et al. (2018b),

24 the level of resistive load induced dyspnea was more than $45 \%$ of the full scale, whereas in the present study the level of resistive load induced dyspnea was only $32 \%$ of the full scale. Alternatively, already the "very weak" to "weak" levels of dyspnea reported by our participants in

27 the baseline condition, might have had a mild impact on neural processing resources and 28 behavioral performance, thereby creating a ceiling effect. In other words, the relative increase in 29 perceived dyspnea between baseline and dyspnea conditions might have been too limited to result 30 in significant further impairments in behavioral accuracy indices. This interpretation would be in 31 line with previous observations (Alius, Pané-Farré, Löw, \& Hamm, 2015), showing that respiring 
1 through a breathing circuit in the absence of an additional resistive load can already impair the

2 neural processing of sensory stimuli such as startle probes. Therefore, in order to increase the

3 difference between the conditions, future studies on recognition memory might benefit from

4 applying higher levels of dyspnea in the dyspnea condition.

6 Even though the implications of this study have yet to be tested in a dyspneic sample, our results 7 still hold potential clinical relevance. The current study shows impaired neural processing of 8 recognition memory during acute dyspnea in healthy participants. Since experimentally induced 9 dyspnea in healthy students cannot fully mimic the existential fear of a chronically dyspneic patient

10 (Currow \& Johnson, 2015; Demoule \& Similowski, 2018; Hayen, Herigstad, \& Pattinson, 2013),

11 it might be argued that similar or even stronger effects of dyspnea on cognitive functioning could 12 be present in affected patients. This could result in several impairments in daily life, such as not 13 following prescriptions to treatment, mixing up or forgetting medications, etc., which might

14 interfere with the disease-management and further contribute to a more unfavorable course of the 15 disease. However, future studies in dyspneic patient groups are clearly needed to investigate these 16 assumptions.

18 Limitations of the present study include the testing of healthy, young, and predominantly female 19 participants, which limits the generalizability of the findings, as well as the induction of only one 20 quality of dyspnea (work and effort to breathe, ATS, 1999). Although similar findings might be 21 observed when using other dyspnea qualities such as air hunger or chest tightness, future studies 22 are warranted, especially in patients suffering from dyspnea, to determine possible effects of other 23 dyspnea qualities on recognition memory. Another limitation of the current study is the absence of 24 any behavioral measures (i.e., confidence ratings) for the underlying recognition memory 25 processes of familiarity and recollection which future studies should incorporate. Furthermore, so 26 far it is not clear whether the suggested dyspnea-cognition interference is specific to dyspnea itself 27 or whether other stressors (i.e., aversive auditory stimulation) might cause a similar effect. 28 Therefore, future studies should include a non-dyspneic stress condition to investigate this. 29 Furthermore, future studies should also explore the effects of dyspnea on the encoding stage of 30 memory processes by applying, for example, a two by two design that compares baseline vs. 31 dyspnea in the encoding vs. retrieval phase. 


\section{References}

Abdi, H. (2007). Signal Detection Theory (SDT). In N. Salkind, Encyclopedia of Measurement

Alexander-Miller, S., \& Davenport, P. W. (2010). Perception of multiple-breath inspiratory resistive loads in males and females. Biological Psychology, 84(1), 147-149. https://doi.org/10.1016/j.biopsycho.2010.03.004

Alius, M. G., Pané-Farré, C. A., Löw, A., \& Hamm, A. O. (2015). Modulation of the blink reflex and $\mathrm{P} 3$ component of the startle response during an interoceptive challenge: Modulation of the blink reflex and P3-component. Psychophysiology, 52(1), 140-148. https://doi.org/10.1111/psyp.12295

Alius, M. G., Pané-Farré, C. A., Von Leupoldt, A., \& Hamm, A. O. (2013). Induction of dyspnea evokes increased anxiety and maladaptive breathing in individuals with high anxiety sensitivity and suffocation fear. Psychophysiology, 50(5), 488-497. https://doi.org/10.1111/psyp.12028

American Thoracic Society, (first). (1999). Dyspnea: mechanisms, assessment, and management. A consensus statement. American Journal of Respiratory and Critical Care Medicine, 159(1), 321-340. https://doi.org/10.1164/ajrccm.159.1.ats898

Banzett, R. B., \& Moosavi, S. H. (2001). Dyspnea and pain: similarities and contrasts between two very unpleasant sensations. APS Bulletin, 11(1), 1-8.

Bloch-Salisbury, E., Lansing, R., \& Shea, S. A. (2000). Acute changes in carbon dioxide levels alter the electroencephalogram without affecting cognitive function. Psychophysiology, 37(4), 418-426. http://dx.doi.org/10.1111/1469-8986.3740418

Borg, G. (1982). Psychophysical bases of perceived exertion. Medicine and Science in Sports and Exercise, 14(5), 377-381. https://doi.org/10.1249/00005768-198205000-00012

Brack, T., Jubran, A., \& Tobin, M. J. (1998). Effect of resistive loading on variational activity of breathing. American Journal of Respiratory and Critical Care Medicine, 157(6), 17561763. http://dx.doi.org/10.1164/ajrccm.157.6.9704114

Bradley, M. M., \& Lang, P. J. (1994). Measuring emotion: The Self-Assessment Manikin and the semantic differential. Journal of Behavior Therapy and Experimental Psychiatry, 25(1), 
49-59. http://dx.doi.org/10.1016/0005-7916(94)90063-9

Celsis, P. (2000). Age-related cognitive decline, mild cognitive impairment or preclinical Alzheimer's disease? Annals of Medicine, 32(1), 6-14. https://doi.org/10.3109/07853890008995904

Clark, R. E. (2013). Recognition Memory: An Old Idea Given New Life. Current Biology, 23(17), R725-R727. https://doi.org/10.1016/j.cub.2013.07.037

Cleutjens, F. A. H. M., Janssen, D. J. A., Ponds, R. W. H. M., Dijkstra, J. B., \& Wouters, E. F. M. (2014). COgnitive-Pulmonary Disease. BioMed Research International, 697825, 1-8. https://doi.org/10.1155/2014/697825

Cleutjens, F., Franssen, F., Spruit, M., Vanfleteren, L., Gijsen, C., Dijkstra, J. B., ... Janssen, D. J. (2016). Domain-specific cognitive impairment in patients with COPD and control subjects. International Journal of Chronic Obstructive Pulmonary Disease, Volume 12, 1-11. https://doi.org/10.2147/COPD.S119633

Curran, T. (1999). The electrophysiology of incidental and intentional retrieval: ERP old/new effects in lexical decision and recognition memory. Neuropsychologia, 37(7), 771-785. https://doi.org/10.1016/S0028-3932(98)00133-X

Currow, D. C., \& Johnson, M. J. (2015). Distilling the essence of breathlessness: the first vital symptom. European Respiratory Journal, 45(6), 1526-1528. https://doi.org/10.1183/09031936.00030115

Demoule, A., \& Similowski, T. (2018). Respiratory Suffering in the Intensive Care Unit: Time for Our Next Great Cause. American Journal of Respiratory and Critical Care Medicine. https://doi.org/10.1164/rccm.201812-2248ED

Dien, J. (1998). Issues in the application of the average reference: Review, critiques, and recommendations. Behavior Research Methods, Instruments, \& Computers, 30(1), 34-43. https://doi.org/10.3758/bf03209414

Dodd, J. W., Getov, S. V., \& Jones, P. W. (2010). Cognitive function in COPD. European Respiratory Journal, 35(4), 913-922. https://doi.org/10.1183/09031936.00125109

Eysenck, M. W., \& Keane, M. T. (2000). Cognitive psychology: A student's handbook, 4th ed. New York, NY, US: Psychology Press.

Finnigan, S. (2002). ERP “old/new" effects: memory strength and decisional factor(s). Neuropsychologia, 40(13), 2288-2304. https://doi.org/10.1016/S0028-3932(02)00113-6 
1 Friedman, D., \& Johnson, R. (2000). Event-related potential (ERP) studies of memory encoding and retrieval: a selective review. Microscopy Research and Technique, 51(1), 6-28. https://doi.org/10.1002/1097-0029(20001001)51:1<6::aid-jemt2>3.3.co;2-i

Gracely, R. H., Undem, B. J., \& Banzett, R. B. (2007). Cough, pain and dyspnoea: similarities and differences. Pulmonary Pharmacology \& Therapeutics, 20(4), 433-437. https://doi.org/10.1016/j.pupt.2006.12.005

Grant, I., Heaton, R. K., McSweeny, A., Adams, K. M., \& Timms, R. M. (1982). Neuropsychologic findings in hypoxemic chronic obstructive pulmonary disease. Archives of Internal Medicine, 142(8), 1470-1476. https://doi.org/10.1001/archinte.1982.00340210062015

Hayen, A., Herigstad, M., \& Pattinson, K. T. S. (2013). Understanding dyspnea as a complex individual experience.

Maturitas,

$76(1)$,

$45-50$. http://dx.doi.org/10.1016/j.maturitas.2013.06.005

Herzog, M., Sucec, J., Van Diest, I., Van den Bergh, O., Chan, P.-Y. S., Davenport, P., \& von Leupoldt, A. (2018). Reduced neural gating of respiratory sensations is associated with increased dyspnoea perception. European Respiratory Journal, 52(1), 1800559. https://doi.org/10.1183/13993003.00559-2018

Herzog, M., Sucec, J., Van Diest, I., Van den Bergh, O., Chenivesse, C., Davenport, P., ... von Leupoldt, A. (2018). Observing dyspnoea in others elicits dyspnoea, negative affect and brain responses. European Respiratory Journal, 5l(4), 1702682. https://doi.org/10.1183/13993003.02682-2017

Herzog, M., Sucec, J., Van Diest, I., Van den Bergh, O., \& von Leupoldt, A. (2019). The presence of others reduces dyspnea and cortical neural processing of respiratory sensations. Biological Psychology, 140, 48-54. https://doi.org/10.1016/j.biopsycho.2018.11.004

Herzog, M., Sucec, J., Vukovic, M., Van Diest, I., Van den Bergh, O., \& von Leupoldt, A. (2019). Experimental social rejection increases dyspnoea perception and neural processing of respiratory sensations in healthy subjects. European Respiratory Journal, 53(1), 1801409. https://doi.org/10.1183/13993003.01409-2018

Huppert, F. A. (1982). Memory impairment associated with chronic hypoxia. Thorax, 37(11), 858860. https://doi.org/10.1136/thx.37.11.858

Ille, N., Berg, P., \& Scherg, M. (2002). Artifact Correction of the Ongoing EEG Using Spatial Filters Based on Artifact and Brain Signal Topographies. Journal of Clinical 
Neurophysiology, 19(2), 113-124. http://dx.doi.org/10.1097/00004691-200203000-00002

Irani, F., Barbone, J. M., Beausoleil, J., \& Gerald, L. (2017). Is asthma associated with cognitive impairments? A meta-analytic review. Journal of Clinical and Experimental Neuropsychology, 39(10), 965-978. https://doi.org/10.1080/13803395.2017.1288802

Johansson, M., Mecklinger, A., \& Treese, A.-C. (2004). Recognition Memory for Emotional and Neutral Faces: An Event-Related Potential Study. Journal of Cognitive Neuroscience, 16(10), 1840-1853. https://doi.org/10.1162/0898929042947883

Juravle, G., Reicherts, P., Riechmann-Weinstein, M., Wieser, M. J., \& von Leupoldt, A. (2017).

Neural responses to affective pictures while anticipating and perceiving respiratory threat: Anticipating and perceiving breathlessness. Psychophysiology, 54(2), 182-192. https://doi.org/10.1111/psyp.12776

Juravle, G., Stoeckel, M. C., Rose, M., Gamer, M., Büchel, C., Wieser, M. J., \& von Leupoldt, A. (2014). Investigating the effect of respiratory bodily threat on the processing of emotional pictures. Respiratory Physiology \& Neurobiology, 204, 41-49. https://doi.org/10.1016/j.resp.2014.05.007

Kessels, R. P. C. (2003). Patients' Memory for Medical Information, 96(5), 219-222. https://doi.org/10.1258/jrsm.96.5.219

Kessler, R., Partridge, M. R., Miravitlles, M., Cazzola, M., Vogelmeier, C., Leynaud, D., \& Ostinelli, J. (2011). Symptom variability in patients with severe COPD: A pan-European cross-sectional study. European Respiratory Journal, 37(2), 264-272. https://doi.org/10.1183/09031936.00051110

Kuhajda, M. C., Thorn, B. E., Klinger, M. R., \& Rubin, N. J. (2002). The effect of headache pain on attention (encoding) and memory (recognition): Pain, 97(3), 213-221. https://doi.org/10.1016/S0304-3959(01)00488-2

Luck, S. J. (2014). An introduction to the event-related potential technique. MIT press.

Malmberg, K. J. (2008). Recognition memory: A review of the critical findings and an integrated theory for relating them. Cognitive Psychology, 57(4), 335-384. https://doi.org/10.1016/j.cogpsych.2008.02.004

Maratos, E. J., Allan, K., \& Rugg, M. D. (2000). Recognition memory for emotionally negative and neutral words: an ERP study. Neuropsychologia, 38(11), 1452-1465. https://doi.org/10.1016/S0028-3932(00)00061-0 
1 McGaugh, J. L. (2004). The amygdala modulates the consolidation of memories of emotionally arousing experiences. Annual Review of Neuroscience, 27(1), 1-28. https://doi.org/10.1146/annurev.neuro.27.070203.144157

Mcguire, L. C. (1996). Remembering what the doctor said: Organization and adults' memory for medical information. Experimental Aging Research, 22(4), 403-428. https://doi.org/10.1080/03610739608254020

McIntyre, R. S., Cha, D. S., Soczynska, J. K., Woldeyohannes, H. O., Gallaugher, L. A., Kudlow, P., ... Baskaran, A. (2013). Cognitive deficits and functional outcomes in major depressive disorder: determinants, substrates, and treatment interventions. Depression and Anxiety, 30(6), 515-527. https://doi.org/10.1002/da.22063

Mecklinger, A. (2000). Interfacing mind and brain: A neurocognitive model of recognition memory. Psychophysiology, 37(05), 565-582. https://doi.org/10.1111/1469-8986.3750565

Miller, M. R., Hankinson, V., Brusasco, V., Burgos, F., Casaburi, R., Coates, A., ... Wanger, J. (2005). Standardisation of spirometry. European Respiratory Journal, 26(2), 319-338. https://doi.org/10.1183/09031936.05.00034805

Moss, M., Franks, M., Briggs, P., Kennedy, D., \& Scholey, A. (2005). Compromised Arterial Oxygen Saturation in Elderly Asthma Sufferers Results in Selective Cognitive Impairment. Journal of Clinical and Experimental Neuropsychology, 27(2), 139-150. https://doi.org/10.1080/13803390490515450

Nierat, M.-C., Demiri, S., Dupuis-Lozeron, E., Allali, G., Morélot-Panzini, C., Similowski, T., \& Adler, D. (2016). When breathing interferes with cognition: experimental inspiratory loading alters timed up-and-go test in normal humans. PLOS ONE, 11(3), e0151625. https://doi.org/10.1371/journal.pone.0151625

Ochsner, K. N. (2000). Are affective events richly recollected or simply familiar? The experience and process of recognizing feelings past. Journal of Experimental Psychology: General, 129(2), 242-261. https://doi.org/10.1037//0096-3445.129.2.242

Parshall, M. B., Schwartzstein, R. M., Adams, L., Banzett, R. B., Manning, H. L., Bourbeau, J., ... O’Donnell, D. E. (2012). An Official American Thoracic Society Statement: Update on the Mechanisms, Assessment, and Management of Dyspnea. American Journal of Respiratory and Critical Care Medicine, 185(4), 435-452. https://doi.org/10.1164/rccm.2011112042ST 
1 Peiffer, C., Costes, N., Hervé, P., \& Garcia-Larrea, L. (2008). Relief of Dyspnea Involves a

Characteristic Brain Activation and a Specific Quality of Sensation. American Journal of Respiratory and Critical Care Medicine, 177(4), 440-449. https://doi.org/10.1164/rccm.200612-1774OC

Raghavan, N., Webb, K., Amornputtisathaporn, N., \& O’Donnell, D. E. (2011). Recent advances in pharmacotherapy for dyspnea in COPD. Current Opinion in Pharmacology, 11(3), 204210. https://doi.org/10.1016/j.coph.2011.03.002

Rugg, M. D., \& Curran, T. (2007). Event-related potentials and recognition memory. Trends in Cognitive Sciences, 11(6), 251-257. https://doi.org/10.1016/j.tics.2007.04.004

Rugg, M. D., Mark, R. E., Walla, P., Schloerscheidt, A. M., Birch, C. S., \& Allan, K. (1998). Dissociation of the neural correlates of implicit and explicit memory. Nature, 392(6676), 595-598. https://doi.org/10.1038/33396

Schloerscheidt, A. M., \& Rugg, M. D. (1997). Recognition memory for words and pictures: an event-related potential study. NeuroReport, 8(15), 3281-3285. https://doi.org/10.1097/00001756-199710200-00018

Shiffrin, R. M., \& Steyvers, M. (1997). A model for recognition memory: REM-retrieving effectively from memory. Psychonomic Bulletin \& Review, 4(2), 145-166. https://doi.org/10.3758/BF03209391

Sterpenich, V., Albouy, G., Darsaud, A., Schmidt, C., Vandewalle, G., Dang Vu, T. T., ... Maquet, P. (2009). Sleep Promotes the Neural Reorganization of Remote Emotional Memory. Journal of Neuroscience, 29(16), 5143-5152. https://doi.org/10.1523/JNEUROSCI.056109.2009

Sucec, J., Herzog, M., Van Diest, I., Van den Bergh, O., \& von Leupoldt, A. (2018a). The impact of dyspnea and threat of dyspnea on error processing. Psychophysiology, 56(1), e13278. https://doi.org/10.1111/psyp.13278

Sucec, J., Herzog, M., Van Diest, I., Van den Bergh, O., \& von Leupoldt, A. (2018b). The impairing effect of dyspnea on response inhibition. International Journal of Psychophysiology, 133, 41-49. https://doi.org/10.1016/j.ijpsycho.2018.08.012

Sucec, J., Herzog, M., Van den Bergh, O., Van Diest, I., \& von Leupoldt, A. (2019). The effects of repeated dyspnea exposure on response inhibition. Frontiers in Physiology.

van Beers, M., Janssen, D. J. A., Gosker, H. R., \& Schols, A. M. W. J. (2018). Cognitive 
impairment in chronic obstructive pulmonary disease: disease burden, determinants and possible future interventions. Expert Review of Respiratory Medicine, 12(12), 1061-1074. https://doi.org/10.1080/17476348.2018.1533405

Van Strien, J. W., Langeslag, S. J. E., Strekalova, N. J., Gootjes, L., \& Franken, I. H. A. (2009).

von Leupoldt, A., \& Dahme, B. (2007). Experimental comparison of dyspnea and pain. Behavior Research Methods, 39(1), 137-143. https://doi.org/10.3758/bf03192852

von Leupoldt, A., Sommer, T., Kegat, S., Baumann, H. J., Klose, H., Dahme, B., \& Büchel, C. (2009). Dyspnea and pain share emotion-related brain network. NeuroImage, 48(1), 200206. https://doi.org/10.1016/j.neuroimage.2009.06.015

Weymar, M., Bradley, M. M., Hamm, A. O., \& Lang, P. J. (2013). When fear forms memories: Threat of shock and brain potentials during encoding and recognition. Cortex, 49(3), 819826. https://doi.org/10.1016/j.cortex.2012.02.012

Weymar, M., Löw, A., \& Hamm, A. O. (2011). Emotional memories are resilient to time: Evidence from the parietal ERP old/new effect. Human Brain Mapping, 32(4), 632-640. https://doi.org/10.1002/hbm.21051

Xu, H., Zhang, Q., Li, B., \& Guo, C. (2015). Dissociable Effects of Valence and Arousal on Different Subtypes of Old/New Effect: Evidence from Event-Related Potentials. Frontiers in Human Neuroscience, 9, 650. https://doi.org/10.3389/fnhum.2015.00650

Yonelinas, A. P. (2002). The Nature of Recollection and Familiarity: A Review of 30 Years of Research. Journal of Memory and Language, 46(3), 441-517. https://doi.org/10.1006/jmla.2002.2864 


\section{Conflict of Interest Statement}

2 The authors declare that there is no conflict of interest related to the present paper.

3

\section{Acknowledgments}

5 This study was supported by grants from the Research Fund KU Leuven, Belgium (STRT/13/002

6 and $\mathrm{DBOF} / 14 / 021)$, by an infrastructure grant from the Herculesstichting, Belgium

7 (AKUL/13/07), and by the "Asthenes" long-term structural funding Methusalem grant

8 (METH/15/011) by the Flemish Government, Belgium. The funders had no role in the design of

9 the study, the collection, and analysis of data, or the preparation of the manuscript. 


\section{Tables}

3 Table 1. Means (SD) for ratings of dyspnea, affective valence and arousal, task difficulty, and task 4 motivation for the baseline and dyspnea condition.

\begin{tabular}{|c|c|c|}
\hline & Baseline & Dyspnea \\
\hline Dyspnea (Borg) & $1.44(1.42)$ & $3.21(1.80)^{* *}$ \\
\hline Valence $(\mathrm{SAM})^{\#}$ & $5.46(1.57)$ & $4.38(1.87)^{* *}$ \\
\hline Arousal (SAM) & $3.90(1.59)$ & $4.27(1.78)^{*}$ \\
\hline Task difficulty (Likert) & $3.26(1.22)$ & $3.59(1.45)^{*}$ \\
\hline Task motivation (Likert) & $5.87(1.08)$ & $5.83(1.07)$ \\
\hline
\end{tabular}

7 Note: Borg $=$ modified Borg scale ranging from 0-10. SAM = Self-Assessment Manikin ranging 8 from 1-9. Likert scale ranging from 1-7. \# Lower valence ratings indicate more unpleasantness. 9 Asterisks indicate a significant difference between the baseline and dyspnea condition with $* \mathrm{p}$ $10<.05, * * \mathrm{p}<.001$. 
1 Table 2. Means (SD) of respiratory variables for the baseline and dyspnea condition.

\begin{tabular}{lcc}
\hline & Baseline & Dyspnea \\
\cline { 2 - 3 } Breathing frequency (f), breaths/minute & $13.85(3.29)$ & $12.03(3.22)^{*}$ \\
Inspiratory time $\left(\mathrm{T}_{\mathrm{I}}\right), \mathrm{s}$ & $2.48(1.10)$ & $3.34(1.18)^{*}$ \\
Tidal volume $\left(\mathrm{V}_{\mathrm{T}}\right), 1$ & $0.57(0.21)$ & $0.54(0.23)$ \\
Mean airflow $\left(\mathrm{V}^{\prime}\right), 1 / \mathrm{s}$ & $0.26(0.09)$ & $0.17(0.05)^{*}$ \\
Peak inspiratory mouth pressure (P $\mathrm{Imax}), \mathrm{cmH}_{2} \mathrm{O}$ & $-1.45(0.42)$ & $-6.22(1.26)^{*}$ \\
End-tidal $\mathrm{CO}_{2}\left(\mathrm{ETCO}_{2}\right), \%$ & $4.75(0.49)$ & $4.94(0.58)^{*}$
\end{tabular}

2 Note: Asterisks indicate a significant difference between the baseline and dyspnea condition with $3 * \mathrm{p}<.001$. 
1 Table 3. Probabilities (SD) in percent for accuracy according to signal-detection theory for the 2 baseline and dyspnea condition.

\begin{tabular}{lcc}
\hline & Baseline & Dyspnea \\
\cline { 2 - 3 } Hit rate $(\mathrm{H})$ & $0.76(0.10)$ & $0.77(0.11)$ \\
False alarm rate (FA) & $0.12(0.07)$ & $0.12(0.07)$ \\
Recognition accuracy (Pr) & $0.64(0.13)$ & $0.66(0.13)$ \\
Response bias (Br) & $0.31(0.13)$ & $0.32(0.17)$
\end{tabular}

3 Note: Recognition accuracy $(\mathrm{Pr}=\mathrm{H}-\mathrm{FA})$; Response bias $(\mathrm{Br}=\mathrm{p}(\mathrm{FA}) / \mathrm{p}(1-\mathrm{Pr}))$ 
1 Table 4. Means (SD) of reaction times for correctly categorized old and new items for the baseline 2 and dyspnea condition.

\begin{tabular}{|c|c|c|c|c|}
\hline & \multicolumn{2}{|c|}{ Baseline } & \multicolumn{2}{|c|}{ Dyspnea } \\
\hline & Old & New & Old & New \\
\hline \multirow{2}{*}{ Reaction time, ms* } & 932.29 & 982.88 & 922.39 & 974.10 \\
\hline & (126.79) & (143.32) & (128.03) & (142.09) \\
\hline
\end{tabular}


1 Table 5. Means (SD) in $\mu \mathrm{V}$ of old-new differences in the ERPs for all latency ranges at fronto2 central sites for the left and right hemisphere for the baseline and dyspnea condition.

\begin{tabular}{lcccc}
\hline & \multicolumn{2}{c}{ Baseline } & \multicolumn{2}{c}{ Dyspnea } \\
\hline & Left & Right & Left & Right \\
\cline { 2 - 5 } $350-500 \mathrm{~ms}^{*}$ & $0.79(0.85)$ & $0.31(0.95)$ & $0.28(0.87)$ & $0.29(1.05)$ \\
$500-800 \mathrm{~ms}^{*}$ & $1.32(0.97)^{\mathrm{a}}$ & $0.65(1.21)$ & $0.66(1.05)^{\mathrm{a}}$ & $0.59(1.27)$ \\
$800-1100 \mathrm{~ms}^{*}$ & $0.83(0.98)$ & $0.83(1.15)$ & $0.43(1.37)$ & $0.43(1.31)$ \\
$1100-1400 \mathrm{~ms}^{*}$ & $0.20(1.08)$ & $0.68(1.24)^{\mathrm{b}}$ & $-0.27(1.32)$ & $0.21(1.36)^{\mathrm{b}}$
\end{tabular}

4 Note: Asterisks indicate a significant difference between the baseline and dyspnea condition for 5 the corresponding latency window with ${ }^{*} \mathrm{p}<.05$. ${ }^{\mathrm{a}}$ indicates a significant difference for the left 6 hemisphere with $\mathrm{p}<.05 .{ }^{\mathrm{b}}$ indicates a significant difference for the right hemisphere with $\mathrm{p}<.05$. 
1 Table 6. Means (SD) in $\mu \mathrm{V}$ of old-new differences in the ERPs for all latency ranges at centro2 parietal sites for the left and right hemisphere for the baseline and dyspnea condition.

3

\begin{tabular}{lcccc}
\hline & \multicolumn{2}{c}{ Baseline } & \multicolumn{2}{c}{ Dyspnea } \\
\hline & Left & Right & Left & Right \\
\cline { 2 - 5 } $350-500 \mathrm{~ms}$ & $0.03(0.85)$ & $-0.14(0.78)$ & $0.05(0.84)$ & $0.07(1.16)$ \\
$500-800 \mathrm{~ms}$ & $0.72(0.93)$ & $0.34(1.02)$ & $0.54(0.90)$ & $0.50(1.32)$ \\
$800-1100 \mathrm{~ms}$ & $0.26(1.23)$ & $0.19(1.21)$ & $0.44(1.36)$ & $0.38(1.40)$ \\
$1100-1400 \mathrm{~ms}$ & $-0.24(1.11)$ & $-0.15(1.14)$ & $-0.15(1.17)$ & $-0.12(1.19)$ \\
\hline
\end{tabular}

4 


\section{Figure legends}

3 Figure 1. Illustration of the electrode selection used with permission from Electrical Geodesics,

4 Inc. The electrode selection for the fronto-central left hemisphere, fronto-central right hemisphere,

5 centro-parietal left hemisphere, and centro-parietal right hemisphere is marked in ruby, purple,

6 green, and yellow color, respectively.

8 Figure 2. Grand average waveforms for the baseline and dyspnea condition combined for the left

9 and right hemisphere at fronto-central (upper panel) and centro-parietal sites (lower panel) for old

10 compared to new items.

12 Figure 3. Grand average waveforms of the old-new difference wave for the baseline and dyspnea 13 condition combined for the left and right hemisphere at fronto-central (upper panel) and centro14 parietal sites (lower panel) with the latency windows 350-500, 500-800, 800-1100, and 1100-1400 15 ms being marked. Scalp topographies represent old-new differences for both conditions (right 16 panel).

18 Figure 4. Mean (SE) of old-new difference scores for the baseline and dyspnea condition 19 combined for the left and right hemisphere at fronto-central sites for the latency ranges 350-500, 20 500-800, 800-1100, and 1100-1400 ms. * $\mathrm{p}<.05$. 